\title{
Article
}

\section{The effects of surface variation on the decomposition of pig carcasses}

\author{
Cogswell, Gregory Charles and Cross, Peter Andrew
}

Available at http://clok.uclan.ac.uk/36726/

Cogswell, Gregory Charles and Cross, Peter Andrew ORCID: 0000-0003-18125664 (2021) The effects of surface variation on the decomposition of pig carcasses. Journal of Forensic and Legal Medicine, 79 (102108). ISSN 1752$928 X$

It is advisable to refer to the publisher's version if you intend to cite from the work. http://dx.doi.org/10.1016/j.jflm.2020.102108

For more information about UCLan's research in this area go to http://www.uclan.ac.uk/researchgroups/ and search for < name of research Group>.

For information about Research generally at UCLan please go to http://www.uclan.ac.uk/research/

All outputs in CLoK are protected by Intellectual Property Rights law, including Copyright law. Copyright, IPR and Moral Rights for the works on this site are retained by the individual authors and/or other copyright owners. Terms and conditions for use of this material are defined in the policies page.

\section{CLoK}

Central Lancashire online Knowledge www.clok.uclan.ac.uk

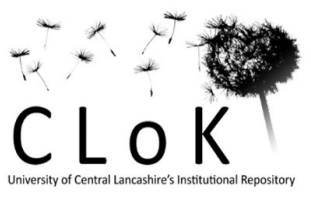




\section{$\underline{\text { Abstract }}$}

Studies investigating the differential decomposition of remains on different surfaces have been limited to qualitative data. This study statistically analyses the differences in rate and pattern of decomposition between concrete, gravel and grass surfaces. A total of 11 pigs (Sus scrofa domesticus) were used in the study: three for the concrete and gravel surfaces each, and 5 for the grass surface. Results showed that there was no difference in the overall rate of decomposition between surfaces $(p>0.05)$; however, there were significant differences in the pattern of decomposition. Mummification was observed on all subjects in the study and may have been the reason for the similarities in the decomposition rates between surfaces. The results of this study show that in the intertwined relationship between factors affecting decomposition surface type may be overshadowed by other environmental factors.

\section{$\underline{\text { Keywords }}$}

Taphonomy, Decomposition, Insect Succession, Postmortem Interval, Concrete, Gravel

\section{Introduction}

Post-mortem interval (PMI) estimation is an important aspect in the medico-legal investigation of human remains. The accurate estimation of PMI may be difficult due to the numerous factors that may influence the process of decomposition. An understanding of how and to what extent specific factors influence this process can aid in the development of more accurate methods of estimating PMI. Subsequent experimental testing using animal models or anecdotal observations ${ }^{1}$ support the factors of temperature ${ }^{2}$ and insect access as being the significant drivers of decomposition. ${ }^{3}$ Whereas other factors that affect the rate of decay previously considered important, may be less so, such as trauma ${ }^{4}$ and clothing. ${ }^{5}$ One factor that has received little attention, however, is the effect the surface a body is lying on has on decomposition.

Previous studies have noted that bodies resting on concrete decompose more slowly and mummify more readily than those resting on natural ground. ${ }^{1,6}$ A recent study ${ }^{6}$ used accumulated degree-days (ADD) ${ }^{7}$ and a decomposition scoring system developed by Galloway ${ }^{8}$ to make basic comparisons of the subjects 
on each surface. The results of the study indicated that the subject placed on concrete decomposed the slowest and spent the longest amount of time in the active decay phase. ${ }^{6}$ In addition, subjects were seen to mummify more readily on concrete. Observations of decomposition on tarpaulin also indicated that the process was slower than natural ground as maggots were seen to suffer high mortality due to drowning in accumulation of fluids from decomposition, collection of rainwater, and humidity of the surface. ${ }^{6,9,10}$ The study concluded that decomposition was slowest on man-made surfaces potentially due to limitations imposed upon insect activity and alteration to normal ground/corpse interaction. Conversely, while observational studies found differences in the rate of decomposition of cadavers on concrete surfaces, another study concluded that the effect of this delayed decomposition was moderate/minimal affecting PMI estimates by only four days. ${ }^{11}$ This study aims to further this work by statistically comparing rates of decomposition on concrete, gravel, and grass surfaces utilizing pigs as a model. Pigs are considered an acceptable analogue in taphonomic and entomological study where human use is not possible. ${ }^{12}$

\section{Materials and Methods}

The experiment took place at the University of Central Lancashire's (UCLAN) research facility, the Taphonomic Research in Anthropology Center for Experimental Study (TRACES). The site is a 13-acre area of rough grassland surrounded by a woodland perimeter located in Lancashire, UK. Due to security reasons the exact location cannot be provided using coordinates.

The grass, gravel and concrete surfaces were prepared prior to the study. The gravel consisted of 10 millimetre (mm) Derbyshire Peakstone, a grey limestone commonly used for driveways and walkways. The gravel was spread over an area of $3 \times 3$ metres $(\mathrm{m})$ at a depth of 3.8-5.1 centimeters $(\mathrm{cm})$. The concrete was laid by a contractor in slabs of similar dimension to the gravel. Both gravel and concrete areas were laid upon a de-turfed layer of topsoil, which extends to a depth of approximately $30 \mathrm{~cm}$ transitioning to clay on top of milnrow sandstone at approximately $1 \mathrm{~m}$. The dimensions of the area were designed to fully isolate the body on the surface by one metre on each side. Three areas each of gravel and concrete were prepared and separated by a distance of at least $10 \mathrm{~m}$. Grass subjects were also separated by a 
distance of at least $10 \mathrm{~m}$. While the generally accepted minimum distance to establish independence of insect colonization between subjects is $50 \mathrm{~m},{ }^{13,14}$ the spacing in this study was limited by the size of the area available within the facility.

The study ran from June $11^{\text {th }}, 2015$ to July $30^{\text {th }}, 2015$ during the late spring and early summer. Subjects were acquired from a local farm where they were humanely dispatched, weighed, transported and deposited at the study facility. Time from dispatch to deposition was approximately four hours. All animals were obtained from a farm, the animals being clinically inspected by a veterinarian prior to slaughter by a competent individual licensed under the Welfare of Animals at Time of Killing Regulations. ${ }^{15}$ Collection, transport, deposition and subsequent disposal of animals remains were conducted in strict compliance with the TRACES biosecurity protocol.

This study utilized 11 domestic pigs (Sus scrofa domesticus) as the subjects. Three pigs were placed on concrete, one on each slab; three on gravel, one on each area; and five pigs were placed on the grass. The average carcass weights on each surface were $30.9 \pm 7.47$ kilograms $(\mathrm{kg}), 38.7 \pm 3 \mathrm{~kg}$, and $43.89 \pm 7.61$ $\mathrm{kg}$ on the concrete, gravel, and grass surfaces, respectively. A linear model was created using the weights of the subjects and the surface type they were deposited on and an analysis of variance (ANOVA) was conducted on the linear model resulting in no significant difference in carcass weight between the surfaces $\mathrm{p}=0.082, \mathrm{~F}=3.48, \mathrm{df}=2$ ). The limitation on numbers of pigs for the concrete and gravel compared to the grass related to the practicality of preparing such areas on a remote location.

A pre-programmed LASCAR EL-USB-1 data logger was inserted rectally to record internal temperature. Each subject was deposited on either a grass, gravel or concrete surface. The subjects were then covered by a $1 \mathrm{~m}$ long, $0.6 \mathrm{~m}$ wide and $0.5 \mathrm{~m}$ tall cage composed of heavy-duty wire with $5 \times 5 \mathrm{~cm}$ openings in order to prevent mammalian scavenger activity but not inhibit insect activity. The cage was labeled for ease of identification. On grass and gravel surfaces the cages do not act as a barrier to insects accessing from beneath. To prevent this occurring with cages on concrete they were raised by placing small wood blocks beneath them. Additional measures to secure the cages were also put in place. 
Temperature data from within the pig was recorded every six hours, as was ambient temperature using LASCAR EL-USB 1 data loggers. This was compared to a local weather station data. Decomposition and entomological data were recorded every three days which equates to approximately every 45 ADD. This data collection interval was selected as a result of known rates of decomposition and insect succession at the location at this time of year and in the prevailing weather conditions at the time. A 45 ADD data collection interval provided adequate sampling to obtain the result needed. Each subject was visually assessed and scored using the Megyesi method as was common during the time the current study was conducted. ${ }^{2,16,17,18}$ Insect activity, including areas of Diptera oviposition and the establishment of larval masses, was also visually assessed and recorded. Samples of maggots were taken at every collection interval, whereafter they were reared to adulthood in the UCLAN entomology lab and where identification was enabled through use of an insect identification key for blow flies and beetles. ${ }^{19,20,21}$

From the temperature data obtained, accumulated degree days (ADD) were calculated for the duration of the study. The temperature threshold of the study was $0^{\circ} \mathrm{C}$. A transformed-mixed-effects model utilising the TBS score as the response variable and the surface type and base log 10 of ADD as the explanatory variables, and the subject number as the random variable was constructed and tested using analysis of covariance (ANCOVA) to determine if there was any significant difference in the decomposition rate of remains between surface groups. Another similar model substituting TBS score with the TBS of each region (head, trunk and limbs) as the response variable was then tested using ANCOVA to determine if there was a difference in the pattern of decomposition between surfaces. A final model combining surface and region into one complex explanatory variable (head/concrete, limbs/gravel, etc.) was plotted. Diagnostic tests indicated that these models needed to be transformed so the base $\log 10$ of ADD was used based on previous studies of decomposition. ${ }^{3,17}$ The statistical analyses were conducted using the statistical software package R-Studio 3.1.1.

\section{$\underline{\text { Results }}$}

Over the duration of the study the average humidity was $60 \%$, total rainfall was $202 \mathrm{~mm}$, and the average 
temperature was $16^{\circ} \mathrm{C} .{ }^{22}$ Weather conditions were initially dry and sunny but became windy with increasing rainfall as the experimental period progressed.

Certain aspects of the decomposition such as, the onset of bone exposure, mummification, and the formation of adipocere, were observed to occur at similar ADD ranges despite the subject's surface (see table 1). In general, the onset of these aspects was observed to occur later for the concrete subjects, but still within the ADD range of the observations of subjects on the other surfaces with the exception of adipocere formation, which may be explained by certain properties of the concrete surface discussed below.

\begin{tabular}{|c|c|c|c|}
\hline & Bone Exposure & Mummification & $\begin{array}{c}\text { Adipocere } \\
\text { Formation }\end{array}$ \\
\hline Concrete & $384-433$ ADD & 493 ADD & $433-660$ ADD \\
\hline Mean & 400 ADD & 493 ADD & 529 ADD \\
\hline Gravel & $239-384$ ADD & $239-493$ ADD & $433-540$ ADD \\
\hline Mean & 336 ADD & 324 ADD & 489 ADD \\
\hline Grass & $251-396$ ADD & $318-505$ ADD & $445-699$ ADD \\
\hline Mean & 399 ADD & 501 ADD & 563 ADD \\
\hline
\end{tabular}

Table 1. ADD range entailing the onset of bone exposure, mummification, and adipocere formation on each surface.

Other unique observations were made for each surface. For instance, while most decomposition fluid was absorbed into the ground, there were areas around the mouth and anus of many of the grass subjects where excess fluids congealed into dark masses (Figure 1).

On the gravel surface, decomposition fluid seeped through the gravel and formed pools of liquid around the mouth and anus that remained throughout the duration of the study. The gravel subjects also exhibited a ring of decomposition staining of the gravel surrounding the subject. This staining was observable throughout the study even after periods of rainfall (Figure 2).

Shortly after the subjects were placed on the concrete purging blood and fluid pooled attracting many flies. Hair and congealed decomposition fluid formed a ring around the subjects. This ring appeared to create a barrier around the body that contained dead flies and maggots (Figure 3).

The general pattern of insect succession on the grass surface began hours after deposition, and larval 
activity was first observed at 127 ADD with large masses observed at 164 ADD. Alternatively, on the gravel and concrete surfaces larval activity was observed at 147 ADD with large masses observed at 189 ADD. Calliphora vicina, Calliphora vomitoria, Lucilia sericata, and Protophormia terraenovae larvae were first collected at 238 ADD (Figure 4). Populations of C. vicina were initially abundant but were eventually overlapped by populations of Calliphora vomitoria along with smaller numbers of Protophormia terraenovae. Fewer samples of Lucilia sericata were observed but only during a very warm period between 305-445 ADD and never on the gravel surface. Adult Piophilidae were first observed as early as 432 ADD on all subjects but observations and collection of their maggot masses was only done on the final day of the study (779 ADD). Beetle (Silphidae) larvae were first observed at 164 and 189 ADD on grass and gravel surfaces, respectively. Finally, for all species except for C. vicina, populations were observed later for the concrete subjects.

There were some exceptions to the pattern of insect succession that were observed on the gravel and concrete surfaces. Mainly, there was a complete lack of Lucilia sericata on the gravel subjects, and only one beetle (Silphidae: Nicrophorus) was ever observed on the concrete subjects at 779 ADD.

At the end of the study the maximum TBS reached was 27 and the minimum was 22 across all replicates. ANCOVA testing of the data showed that there was no significant difference in the overall decomposition of remains between the surface groups $(\mathrm{p}=0.56, \mathrm{~F}=0.59, \mathrm{df}=2)$. Comparing the regression lines for each surface (table 2) shows that while the rate of decomposition, or the slope, of these lines do not differ significantly, there are differences in the intercept which may be due to differences in the pattern of decomposition.

\begin{tabular}{|c|c|c|c|}
\hline & Concrete & Gravel & Grass \\
\hline Slope & 13.657 & 14.995 & 14.235 \\
\hline Intercept & -16.354 & -18.796 & -16.695 \\
\hline
\end{tabular}

Table 2. Comparison of the values of the slope and intercepts of the regression lines of each surface.

Although there was no significant difference in the rate of decomposition, figure 5 shows that the regression line representing the concrete surface has the shallowest slope, especially in the later stages 
of decomposition, and gravel had the steepest slope. While there was no significant difference in the rate of decomposition across surface type, the differences in the slope may have become significant had the studied continued for a longer period than alloted.

Since TBS is an aggregate score of three regions of the body, investigation into the decomposition of each region was done to determine if there were differences in the pattern of decomposition between surfaces. Results of ANCOVA testing showed significant differences in the decomposition pattern of the head between the grass and gravel surfaces $(\mathrm{p}=0.02, \mathrm{t}=2.32, \mathrm{df}=134)$, decomposition of the trunk between the concrete and gravel surfaces $(\mathrm{p}<0.01, \mathrm{t}=3.11, \mathrm{df}=134)$, and decomposition of the limbs between the concrete and gravel surfaces $(\mathrm{p}=0.02, \mathrm{t}=2.34, \mathrm{df}=134)$. Specifically, the head decomposed slower on the grass surface than on gravel, the trunk decomposed slower on concrete surfaces than on gravel, and the limbs decomposed slower on the concrete surfaces than on the gravel surfaces. These differences may account for the difference in the intercepts of the regression lines for each surface that were compared in table 2 and figure 5.

Comparison of TBS over ADD for each surface/region variable showed that decomposition of the head progressed the fastest and was followed by the trunk, then limbs on all surfaces; however, the trunk on the concrete decomposed slower than the limb region on the gravel and grass surfaces (Figure 6).

\section{$\underline{\text { Discussion }}$}

While observational data appeared to support previous studies, ${ }^{1,6}$ especially during the early stages of decomposition, statistically the differences were found to be insignificant and indicated that overall the subjects decomposed at the same rate for grass, gravel and concrete surfaces. This is similar to findings by Anton et al. that concluded that PMI for carcasses on concrete surfaces were only four days behind natural ground during the summer ${ }^{11}$. Statistical significance was found in the pattern of decomposition of subjects on each surface, echoing conclusions by Matuszewski et al. that decomposition progresses in a mosaic fashion ${ }^{9}$. Bone exposure generally occurred the latest for the concrete subjects, especially in the trunk region. Even when bone exposure was observed on the trunk of the concrete subjects it was 
limited to exposure of the coccygeal vertebrae. Shattuck postulated that the slower decomposition rate observed on the concrete may be due to the physical properties of the surface being inhospitable to burrowing insects . ${ }^{6,11}$ This idea is supported by the conclusions of Dekeirsschieter et al. who also noticed an absence of silphids at their concrete site ${ }^{23}$, and Anton et al., who observed increased insect activity in more natural regions, especially during the spring. ${ }^{11}$ While insect activity in these studies were observed to be hindered slightly, certain adaptive strategies were observed in current study as insects removed the skin on the inferior side of the head on concrete surfaces while leaving the skin above for possible shelter $^{24}$ This behavior is similar to what was observed by Anton et al. who noticed egg clutches located on the underside of carrion on the concrete surface. ${ }^{11}$

An alternative explanation for the slower decomposition rate may have to do with the microscopic properties of the concrete surface. Concrete possesses antimicrobial properties due to the high alkalinity that results from its construction ${ }^{25,26}$; however, if concrete is exposed to conditions such as, wastewater pipelines and the floors of barns housing animals, then the microbial activity can penetrate the protective properties and then quickly deteriorate the porous structure of the concrete. ${ }^{23,25}$ This could explain why the concrete subjects in the current study initially lagged behind the subjects on the other surfaces, but then appeared to catch up as the study progressed to the point that there was no significant difference in the rate of decomposition.

Additionally, the accumulation of water from rainfall combined with the decreased humidity at the ground-corpse inteface may have stalled Calliphoridae activity. While humidity was not recorded on each surface, research has shown that concrete has a high thermal mass, meaning it possesses the ability to absorb heat and release it slowly over time. ${ }^{28}$ The energy from heat causes water to evaporate and create humidity. If a surface with a high thermal mass dissipates heat slowly, less water will evaporate and create a lower relative humidity when compared to other surfaces. Matusziewski et al. observed that forest floors with higher humidity levels exhibited higher Calliphoridae oviposition as well as, an increased chance of eggs hatching. ${ }^{9}$ The general characteristic of concrete to have low humidity at the 
surface may be why most insect activity lagged behind (see table 3 ) when compared to other surfaces early on as oviposition and chances of eggs hatching were not as high as on other surfaces. Also, concrete is also not as porous as gravel nor as absorbent as natural ground meaning that periods of rainfall—which have been shown to hinder insect flight activity ${ }^{11}$ - can drown maggots and inhibit their ability to pupate. ${ }^{6}$, 10

Insect activity was first observed at $127 \mathrm{ADD}$ with masses forming at $164 \mathrm{ADD}$ on the control subjects while first activity on the concrete was first observed at 164 ADD with established masses at 189 ADD. These results are similar to previous studies conducted at TRACES ${ }^{3,4}$ and a concurrent study that utilised the same control group. ${ }^{29}$ Due to observations being conducted approximately every 45 ADD, it is possible that insect activity could have occurred sooner than what was observed.

The delay in the onset of insect activity may be due to a phenomenon observed in multiple decomposition studies conducted throughout Europe. Matuszewski et al. conducted a study in the forests of Central Europe and found that in consecutive years decomposition in the spring was slower than in the summer and autumn seasons. ${ }^{9}$ The study observed a significant delay in the onset of the active decay phase for these subjects and postulated that the onset of the active decay phase - which the authors defined as the first day that a mass of larvae is present — was being delayed because insect activity was delayed. Another study conducted in Germany by Anton et al. noted that during the spring, egg clutches were first observed on the ninth day of the study with maggot activity first observed on the $14^{\text {th }}$ day of the study for the subject on the concrete surface, while decomposition during the summer and late summer studies proceeded much more rapidly. ${ }^{11}$ The findings of these studies indicate that in Europe, early decomposition in spring is slightly delayed and may be due to a later onset of insect activity.

Differences between the aforementioned studies and the current one should be noted. Specifically, the current study began in June and experienced only 11 days of spring while the previous studies began in April. As a result, mean temperatures in the current study were higher, $\mathrm{T}_{\text {mean }}=15^{\circ} \mathrm{C}$, than in the study by Matuszewski et al. $\mathrm{T}_{\text {mean }}=13^{\circ} \mathrm{C}^{9}$, or by Anton et al. $\mathrm{T}_{\text {mean }}=5-10^{\circ} \mathrm{C} .{ }^{11}$ Finally, comparison of the onset of 
insect activity was difficult due to the current study calculating PMI using ADD while the previous studies used days postmortem. Despite these differences however; it could be possible that the beginning of the current study may have been replicating this phenomenon since larval activity was only first observed at $127 \mathrm{ADD}$ and there were extended periods of early decomposition observed, especially on the concrete surface.

One reason for the similarities in decomposition rate may have been due to the weight of the subjects on each surface. Statistical testing showed there was no significant difference in the weights of the subjects between surfaces; however, the fact that subjects on the concrete surface were lower in weight on average than those on the grass surface $(30.9 \pm 7.47 \mathrm{~kg}$ and $43.89 \pm 7.61$, respectively) could have served to equalize the decomposition rates between surfaces. Previous studies have found that when blow fly activity is the driving factor carcass weight affects the rate of decomposition. ${ }^{2,3,30}$ Typically, the more of a carcass there is to consume, the longer it takes for the carcass to decompose. Therefore, the similarity in the rates of decomposition on the concrete and grass surfaces could be a result of the difference in subject weights and this could have reduced the effect that surface type has on the rate of decomposition. Another reason for the similarities in decomposition rate may be due to the desiccation of the subjects. Dessication may lead to mummification and occurs when there are barriers to the bacteria or insects crucial to the decomposition. ${ }^{31}$ Previous observations noted that subjects on concrete surfaces succumbed to mummification more readily than other subjects. ${ }^{1,6}$ Galloway found that bodies in the ArizonaSonoran desert usually experienced mummification between 10-30 days post-mortem. ${ }^{8}$ These bodies were characterized by a leathery layer of skin covering underlying soft tissue with a strong odour that dissipated over time, insect activity, and little bone exposure. Environments such as crypts and catacombs are characterized by cool and dry conditions that are conducive to desiccation, which may partially explain why studies investigating decomposition on concrete surfaces exhibit desiccation. ${ }^{31,1,6}$ This was not the case for the current study, however, since bodies on the gravel and grass surfaces mummified just as readily, if not faster. 
Throughout the study, there was an estimated $202 \mathrm{~mm}$ of rainfall. However, the initial 305 ADD of the study featured long periods of little to no rainfall. ${ }^{22}$ These cool and dry weather characteristics early on could have attributed to the early desiccation of the subjects. Additionally, TRACES experiences strong winds which may also lead to rapid desiccation. ${ }^{32}$ The second half of the study exhibited longer periods of frequent rainfall. Rain would collect on the subjects resulting in pools that would drown maggots. The heavier rainfall after the desiccation of the remains may also be partially responsible for why most subjects stalled at a TBS of 24 for so long as it appeared to stall oviposition and drown feasting maggots. Also, during this period of heavier rainfall there was adipocere formation as early as 433 ADD. Adipocere is known to preserve soft tissue for an extended duration as well as provide a barrier to bacterial and insect activity. Therefore, the formation of adipocere on $100 \%$ of the concrete subjects as opposed to $66 \%$ on the gravel and only $50 \%$ on the grass subjects may be an indication that concrete subjects decompose slower as suggested in previous studies. ${ }^{1,6}$

Despite the increased propensity for adipocere to form in this study, desiccation and subsequent mummification was observed in a majority of the subjects regardless of the surface it was deposited on. Adipocere and mummification have been noted to occur in tandem as adipocere does not require exogenous hydration to form. ${ }^{24,33,34}$ Adipocere and mummification are two processes that prolong soft tissue preservation and their propensity to materialize in the cool and windy, and subsequently warm and wet environment found at TRACES may have been the reason that no significant differences were found in the decomposition rates of subjects between surfaces. Therefore, Mann et al.'s conclusion that surface has a low-level effect on decomposition rate appears correct when compared to the overall effects of climate on all subjects. ${ }^{1}$

While TBS has been shown to be one of the best observational variables ${ }^{7,18}$, there is some issue with how it relates to rapid mummification. Typically, bone exposure occurs first followed by mummification and thus, is only scored in conjunction with bone exposure. ${ }^{16}$ Mummification occurred shortly after bone exposure and sometimes even before bone exposure occurred. This phenomenon could over or 
underestimate the stage of decomposition a subject is in. Early mummification can stall the later stages of decomposition as the desiccated skin can become an inhospitable environment for blowfly eggs. ${ }^{32}$ Perhaps if the study had continued to the skeletonisation, then significant differences may have been seen.

The skeletonisation stage coincides with a TBS of about 27 or more and thus occurs at roughly $1285 \pm$ 110 ADD. $^{7}$ The results of the current study indicate that there is no significant difference in the decomposition rates between surfaces, thus one equation could be used to estimate ADD based on the TBS recorded. The equation derived from the regression line for the grass surface was used as it represents the intermediate rate between concrete and gravel:

$$
A D D=10^{\frac{(T B S+16.695)}{14.235}}
$$

Inputting a TBS of 27 into the above equation results in an estimated ADD of 1174 . This is just barely one ADD outside of the estimate calculated by Vass et $a l .^{7}$ While this value coincides closely with the previous findings, the $95 \%$ prediction intervals maintain a much wider estimate. The prediction intervals were much larger as the study continued, especially for the concrete surface indicating that further differences in decomposition rate may be observed if the study were to continue to the skeletonisation stage.

Flies and eggs were present on all surfaces at early stages in the study and maggot masses flourished during similar time periods; however, all but one species of insect observed (C. vicina) in this study were observed at slightly later times on the concrete surface than on the other surfaces (Figure 4). The biggest difference concerning insects was the absence of beetles and beetle larvae on the concrete subjects. Only one beetle was ever observed on the concrete surfaces and that was on the final day of the study. In contrast, the gravel and grass subjects showed extensive beetle larva colonisation as early as 164 ADD. It is unknown why the beetle activity was absent on concrete subjects. This observation appears even 
more significant given that the distances between the surface groups did not meet the $50 \mathrm{~m}$ threshold to ensure independence of insect activity. ${ }^{13,14}$

The concrete subjects exhibited a ring of congealed decomposition fluids surrounding the body. Within this congealed fluid were numerous dead flies and maggots. There were no beetles observed within this congealed fluid. This indicates that either beetles were avoiding the surface altogether or they were being removed before reaching the subjects. Avian activity in the form of excrements and feathers were observed mainly on the concrete and gravel surfaces. The birds may have been feasting on the insects on these surfaces as they are more open to predation. ${ }^{24}$

Shattuck similarly noticed a delay in beetle activity on the pig on the concrete surface. ${ }^{6}$ While most other subjects saw beetle activity by the tenth day it was not until day 17 that beetles were observed on their concrete subject. Dekeirsschieter et al. noted a complete lack of silphid activity, although their concrete site was on the second floor of an industrial building, while Anton et al. noted some decreased activity of beetles at their concrete site at the side of a building near grassland. ${ }^{11}$ The general explanation being that reduced access to ground where they can burrow causes them to avoid such surfaces. ${ }^{11}$

Beetles are an important part of the decomposition as they possess strong mouth parts capable of tearing flesh. ${ }^{35}$ Without populations of beetles to colonise the subjects there is nothing to consume the flesh of the subjects. This becomes important in the later stages of decomposition since limited consumption of skin increases the chances of mummification. This may be why subjects on concrete surfaces mummify readily and thus, decompose at a slower rate. A continuation of this study may have shown a more significant change in the decomposition rate as the beetles on the grass and gravel surfaces may rapidly transition the change to skeletonisation.

\section{Conclusion}

While the current study was the first to statistically assess the rate of decomposition on various surfaces, there were limitations to the study that necessitate additional research. One limitation was the amount of subjects available for statistical analysis. An increase in subjects for each surface group would allow for 
more statistical significance.

Results indicated that more differences would be observed if the study could have continued to the skeletonisation stage of decomposition. A subsequent study that allows for enough time to elapse could be beneficial in understanding the later stages of decomposition on each surface. Furthermore, previous studies conducted in Europe show a marked difference in decomposition depending on the season. ${ }^{9,} 11$ Additional studies investigating if there is any relationship between season and surface type could prove to be insightful. Finally, the apparent effect of the environment that lead to mummification on all surfaces shows that additional studies need to be conducted in different environments and with additional surface types.

This study was conducted in an attempt to reveal if there was any significant difference in the decomposition rate of bodies resting on different surfaces. Analysis of the decomposition rates of subjects on different surfaces revealed no significant differences, but the unique characteristics of each surface created differential access to insects leading to a difference in the pattern of decomposition between surfaces, especially when it came to beetle colonisation. Other environmental factors leading to rapid desiccation of the subjects may have altered the decomposition rates more than surface variation, but that only highlights the importance of replicate testing in different environments.

Additionally, throughout this study, multiple observations were made on the deterioration of the concrete surfaces beneath the subjects and the rings of decomposition surrounding them. These observations may indicate that it is possible to determine if a body spent time on a concrete surface before being moved to a subsequent location. Further studies on the properties of concrete and how decomposition affects concrete surfaces could be helpful in understanding the relationship between the decomposing subject and the surface it rests upon.

This study attempts to answer questions that are vital to the forensic process. No new estimate for PMI is required regarding surface variation as it appears to play an insignificant role in the rate of decomposition in this particular environment. Further testing in new environments, with larger sample 
sizes, and a longer time frame are necessary for a more thorough understanding of this topic and the creation of more accurate PMI.

\section{$\underline{\text { Works Cited }}$}

1. Mann RW, Bass WM, Meadows L. Time Since Death and Decomposition of the Human Body: Variables and Observations in Case and Experimental Field Studies. Journal of Forensic Sciences. 1990;35(1). doi:10.1520/jfs12806j

2. Matuszewski S, Konwerski S, Frątczak K, Szafałowicz M. Effect of body mass and clothing on decomposition of pig carcasses. International Journal of Legal Medicine. 2014;128(6):10391048. doi:10.1007/s00414-014-0965-5

3. Simmons T, Adlam RE, Moffatt C. Debugging Decomposition Data--Comparative Taphonomic Studies and the Influence of Insects and Carcass Size on Decomposition Rate. Journal of Forensic Sciences. 2010;55(1):8-13. doi:10.1111/j.1556-4029.2009.01206.x

4. Cross P, Simmons T. The Influence of Penetrative Trauma on the Rate of Decomposition. Journal of Forensic Sciences. 2010;55(2):295-301. doi:10.1111/j.1556-4029.2009.01277.x

5. Card A, Cross P, Moffatt C, Simmons T. The Effect of Clothing on the Rate of Decomposition and Diptera Colonization on Sus scrofa Carcasses. Journal of Forensic Sciences. 2015;60(4):979-982. doi:10.1111/1556-4029.12750

6. Shattuck CM. An analysis of decomposition rates on outdoor surface variations in central Texas. 2009.

7. Vass AA, Bass WM, Wolt JD, Foss JE, Ammons JT. Time Since Death Determinations of Human Cadavers Using Soil Solution. Journal of Forensic Sciences. 1992;37(5). doi:10.1520/jfs $13311 \mathrm{j}$

8. Sorg MH, Haglund WD, Marden K, Galloway A. The process of decomposition: a model from the Arizona-Sonoran desert. In: Forensic Taphonomy: the Postmortem Fate of Human Remains. Boca Raton, FL: CRC Press; 1997:139-150.

9. Matuszewski, S., Bajerlein, D., Konwerski, S., \& Szpila, K. (2010). Insect succession and carrion decomposition in selected forests of Central Europe. Part 1: Pattern and rate of decomposition. Forensic Science International, 194(1-3), 85-93. doi:10.1016/j.forsciint.2009.10.016

10. Bugajski, K. N., \& Tolle, C. (2014). Effect of Water on Blow Fly (Diptera: Calliphoridae) Colonization of Pigs in Northwest Indiana. Proceedings of the Indiana Academy of Science, 123(1), 67-71. Retrieved from https://journals.iupui.edu/index.php/ias/article/view/22478/21969

11. Anton, E., Niederegger, S., \& Beutel, R. G. (2011). Beetles and flies collected on pig carrion in 
an experimental setting in Thuringia and their forensic implications. Medical and Veterinary Entomology, 25(4), 353-364. doi:10.1111/j.1365-2915.2011.00975.x

12. Matuszewski S, Hall MJR, Moreau G, Schoenly KG, Tarone AM, Villet MH. Pigs vs people: the use of pigs as analogues for humans in forensic entomology and taphonomy research. International Journal of Legal Medicine. 2019;134(2):793-810. doi:10.1007/s00414-01902074-5

13. Byrd JH, Castner JL. Forensic Entomology: the Utility of Arthropods in Legal Investigations. Boca Raton: CRC Press; 2010.

14. Catts EP. Problems in Estimating the Postmortem Interval in Death Investigations. Journal of Agricultural Entomology . 1992;9(4):245-255.

doi:https://scentsoc.org/Volumes/JAE/v9/4/00094245.pdf

15. The Welfare of Animals at the Time of Killing (England) Regulations 2015. Legislation.gov.uk. http:/www.legislation.gov.uk/uksi/2015/1782/contents/made. Accessed May 5, 2015.

16. Megyesi MS, Nawrocki SP, Haskell NH. Using Accumulated Degree-Days to Estimate the Postmortem Interval from Decomposed Human Remains. Journal of Forensic Sciences. 2005;50(3):1-9. doi:10.1520/jfs2004017

17. Heaton V, Lagden A, Moffatt C, Simmons T. Predicting the Postmortem Submersion Interval for Human Remains Recovered from U.K. Waterways. Journal of Forensic Sciences. 2010;55(2):302-307. doi:10.1111/j.1556-4029.2009.01291.x

18. Myburgh J, L'Abbé EN, Steyn M, Becker PJ. Estimating the postmortem interval (PMI) using accumulated degree-days (ADD) in a temperate region of South Africa. Forensic Science International. 2013;229(1-3). doi:10.1016/j.forsciint.2013.03.037

19. Erzinçlioğlu Zakaria. Blowflies. Slough: Published for the Company of Biologists by the Richmond Pub. Co.; 1996.

20. Hammond, P. M., Marshall, J. E., \& Cox, M. L. (2019). British Coleoptera larvae: A guide to the families and major subfamilies. St Albans: Published for the Royal entomological Society by the Field Studies Council.

21. Oosterbroek, P. (2006). The European families of the Diptera: Identification, diagnosis, biology. Utrecht: KNNV Publishing.

22. Burnley, Lancashire, United Kingdom Monthly Weather. AccuWeather. http://www.accuweather.com/en/gb/burnley/bb11-1/March-weather/329010. Published 2015. Accessed May 5, 2015.

23. Dekeirsschieter, J., Verheggen, F. J., Haubruge, E., \& Brostaux, Y. (2011). Carrion Beetles Visiting Pig Carcasses during Early Spring in Urban, Forest and Agricultural Biotopes of 
Western Europe. Journal of Insect Science, 11(73), 1-13. doi:10.1673/031.011.7301

24. Sorg MH, Haglund WD, Marden K, Bass WM. Outdoor decomposition rates in Tennessee. In: Forensic Taphonomy: the Postmortem Fate of Human Remains. Boca Raton, FL: CRC Press; 1997:181-186.

25. Wei S, Jiang Z, Liu H, Zhou D, Sanchez-Silva M. Microbiologically induced deterioration of concrete: a review. Brazilian Journal of Microbiology. 2013;44(4):1001-1007. doi:10.1590/s1517-83822014005000006

26. Sand W. Importance of Hydrogen Sulfide, Thiosulfate, and Methylmercaptan for Growth of Thiobacilli during Simulation of Concrete Corrosion. Applied and Environmental Microbiology. 1987;53(7):1645-1648. doi:10.1128/aem.53.7.1645-1648.1987

27. Sanchez-Silva M, Rosowsky DV. Biodeterioration of Construction Materials: State of the Art and Future Challenges. Journal of Materials in Civil Engineering. 2008;20(5):352-365. doi:10.1061/(asce)0899-1561(2008)20:5(352)

28. Shafigh, P., Asadi, I., \& Mahyuddin, N. B. (2018). Concrete as a thermal mass material for building applications - A review. Journal of Building Engineering, 19, 14-25. doi:10.1016/j.jobe.2018.04.021

29. Weger, M., Cross, P., \& Cunliffe, R. (2020). The effect of plastic bag containment of the head on the rate and pattern of decomposition. Journal of Forensic and Legal Medicine, 71, 101922. doi:10.1016/j.jflm.2020.101922

30. Roberts, L. G., Spencer, J. R., \& Dabbs, G. R. (2017). The Effect of Body Mass on Outdoor Adult Human Decomposition. Journal of Forensic Sciences, 62(5), 1145-1150. doi:10.1111/1556-4029.13398

31. Lynnerup N. Mummies. American Journal of Physical Anthropology. 2007;134(S45):162-190. doi:10.1002/ajpa.20728

32. Aturaliya S, Lukasewycz A. Experimental Forensic and Bioanthropological Aspects of Soft Tissue Taphonomy: 1. Factors Influencing Postmortem Tissue Desiccation Rate. Journal of Forensic Sciences. 1999;44(5). doi:10.1520/jfs12011j

33. Sorg MH, Haglund WD, Marden K, Clark MA, Worrel MB, Pless JE. Postmortem changes in soft tissues. In: Forensic Taphonomy: the Postmortem Fate of Human Remains. Boca Raton, FL: CRC Press; 1997:151-164.

34. Ubelaker DH, Zarenko KM. Adipocere: What is known after over two centuries of research. Forensic Science International. 2011;208(1-3):167-172. doi:10.1016/j.forsciint.2010.11.024

35. Catts EP, Goff ML. Forensic Entomology in Criminal Investigations. Annual Review of 
Entomology. 1992;37(1):253-272. doi:10.1146/annurev.en.37.010192.001345 


\section{Figures:}

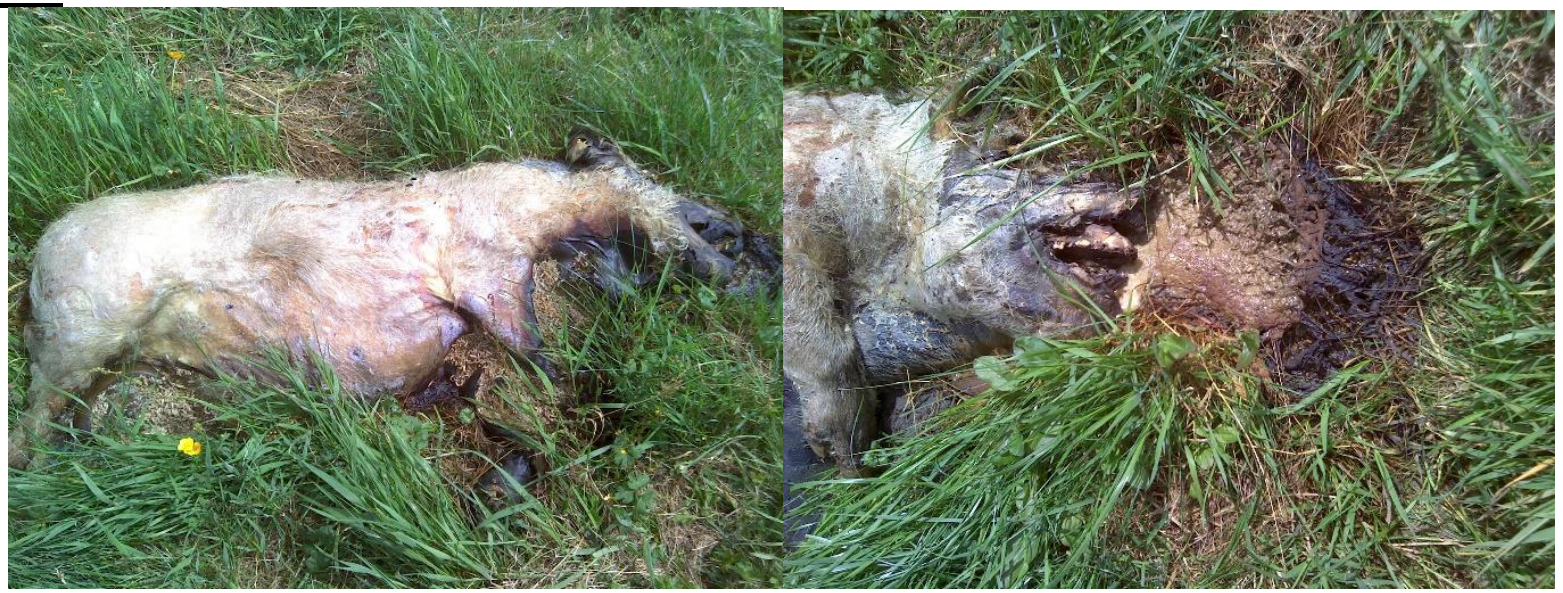

Figure 1. Images of one of the grass (control) subjects at 305 ADD and an overall TBS scored at 19.

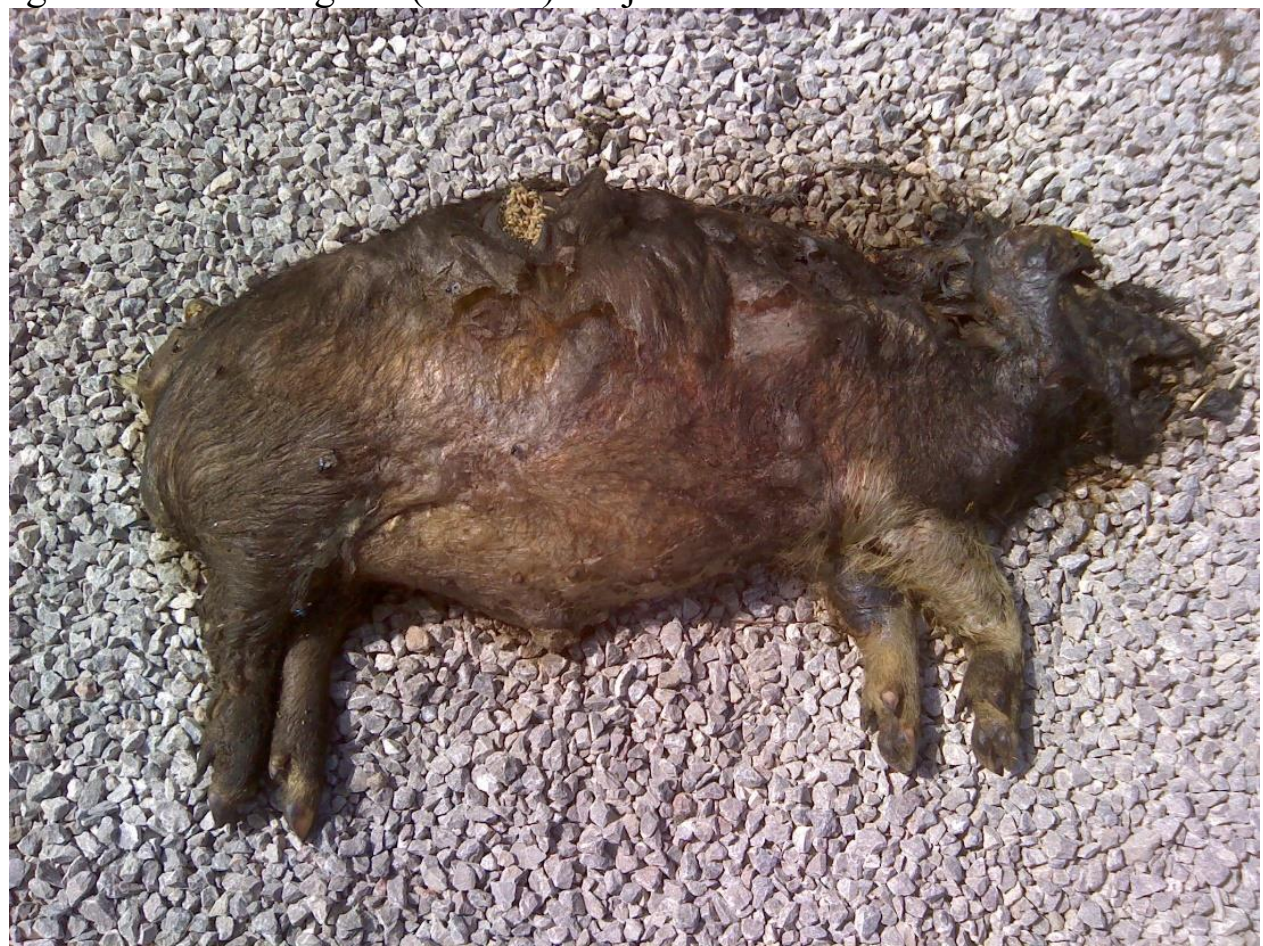

Figure 2. Image of one of the gravel subjects at 305 ADD and an overall TBS scored at 21. Staining of the gravel can be observed around the head region. 


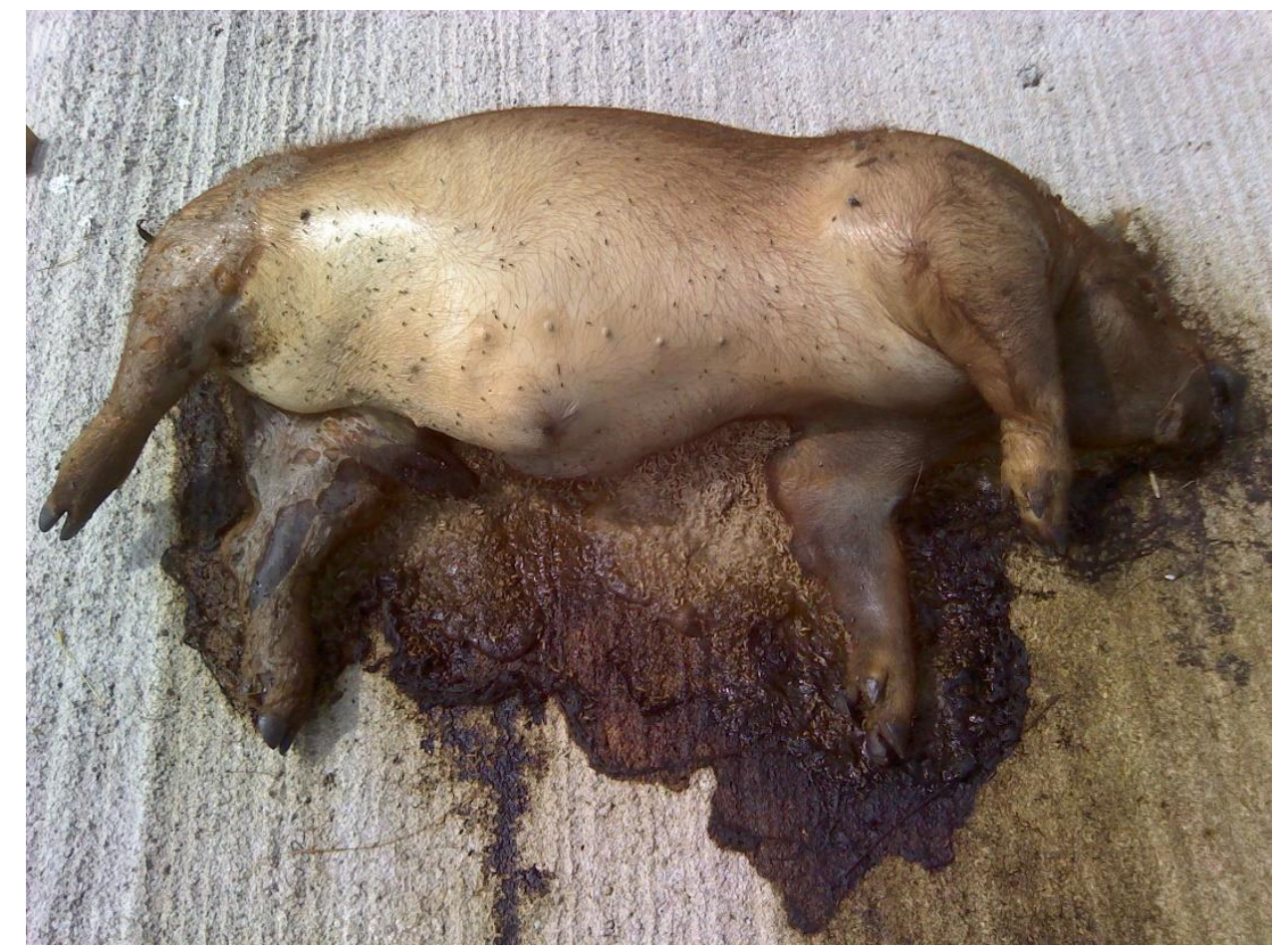

Figure 3. Image of one of the concrete subjects at 305 ADD and an overall TBS scored at 18. Also seen in this image is the accumulation of decomposition fluid that was observed on all concrete subjects and the large amount of maggots contained within that fluid.

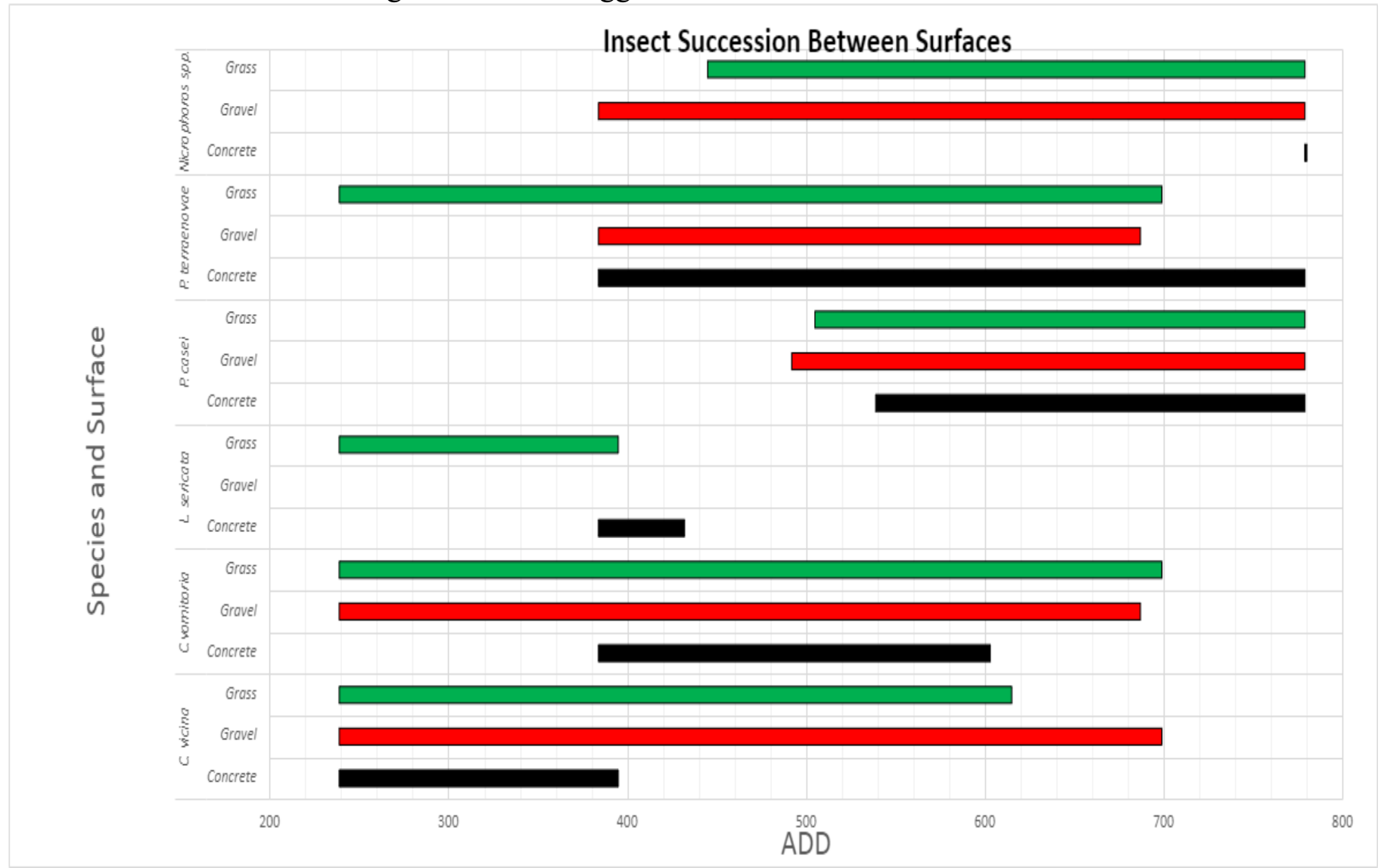

Figure 4. Bar graph showing occurrence and duration of insect species on each surface throughout the study. Migrating maggots were collected and then reared to adulthood where they were then identified. 
Beetle larvae were not collected, but observed.

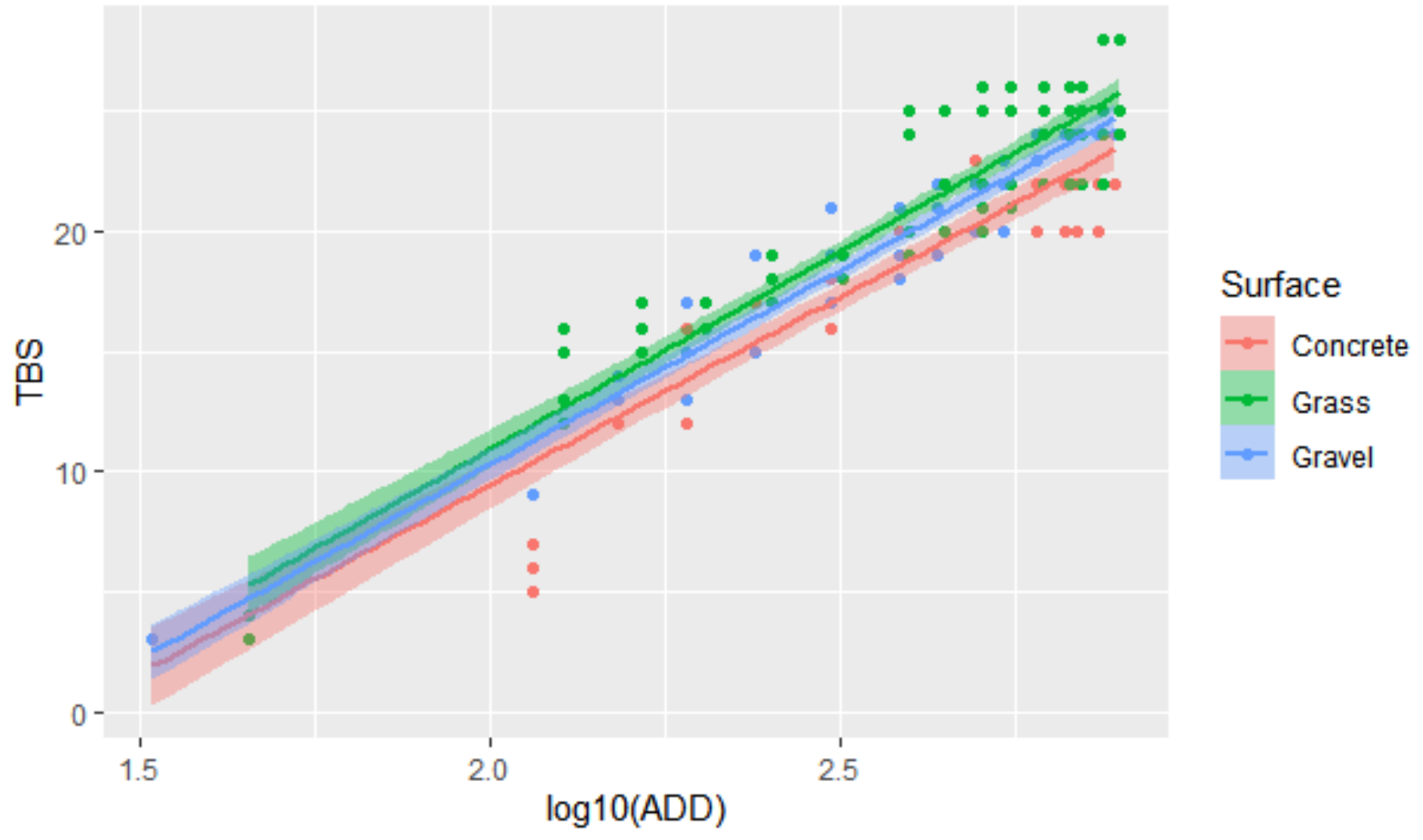

Figure 5. Plot of the overall decomposition of subjects with added regression lines and $95 \%$ confidence interval bands representing the rates of decomposition on each surface.

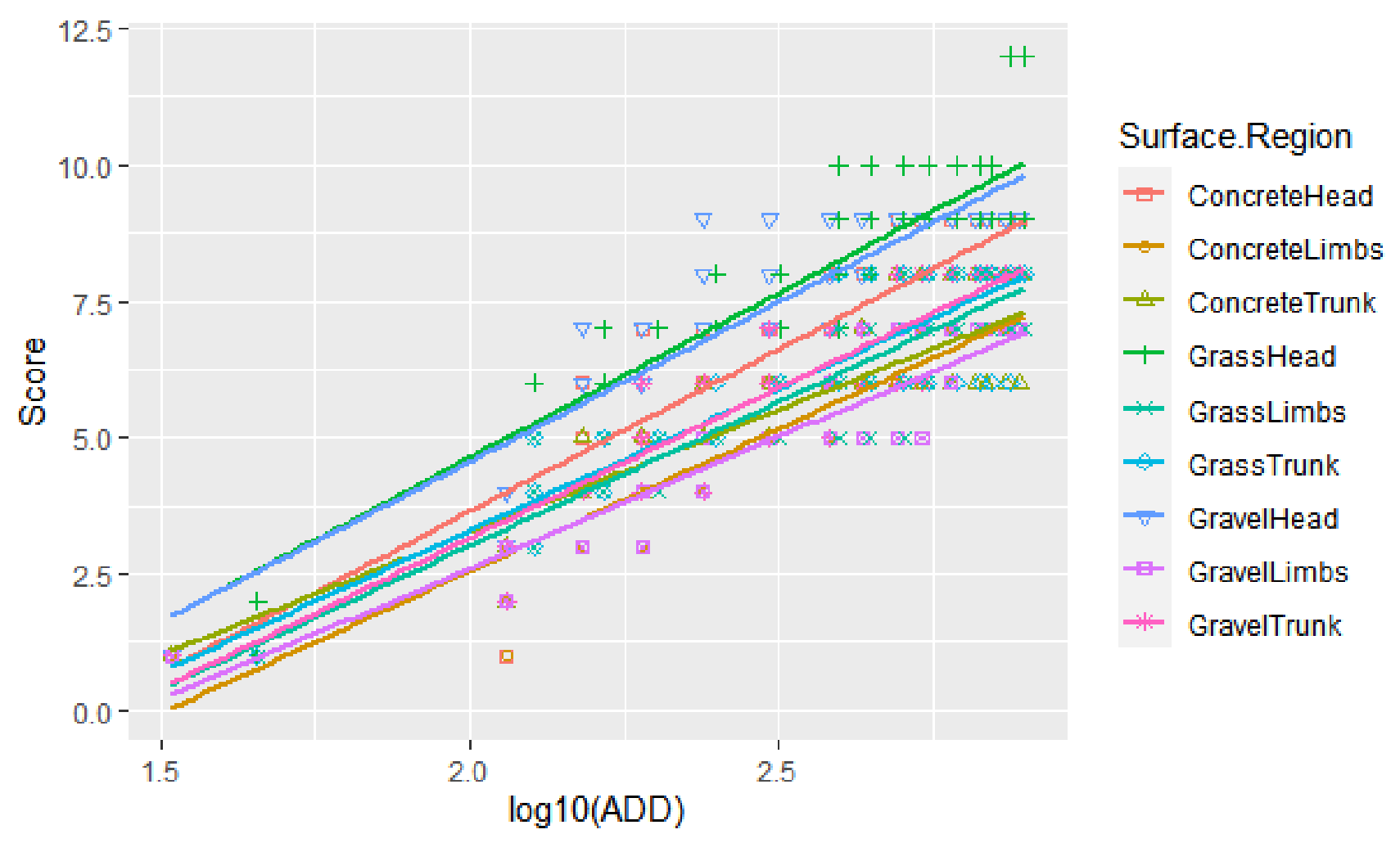

Figure 6. Comparison of the decomposition rates of each surface and region combined. The top graph is presented with 95\% confidence interval bands, while the bottom graph has them removed for $\mathrm{c}$ 